\title{
RESEÑA
}

\section{US Hegemony and the Americas: Power and Economic Statecraft in International Relations}

DOI: 10.32870/mycp.v9i26.695

Miguel Hijar-Chiapa ${ }^{1}$

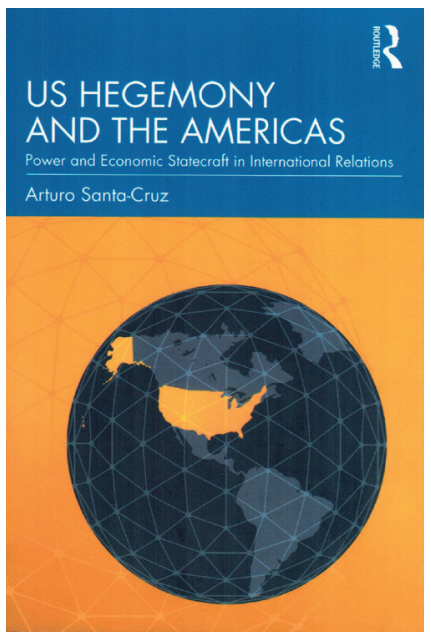

Santa-Cruz, Arturo. (2020). US Hegemony and the Americas: Power and Economic Statecraft in International Relations. Oxon: Routledge.

Tras la victoria aliada en la Segunda Guerra Mundial, la Pax Britannica, el periodo durante el cual el Imperio Británico fue el hegemón global, llegó a su fin y con ello una nueva potencia tomó esa batuta: Estados Unidos. Desde entonces, un nuevo orden mundial fue estructurado a través de un conjunto de instituciones y normas construidas, en gran medida, por Estados Unidos y sus aliados, permitiéndole proyectar su poder alrededor del orbe. Pero no había otro lugar en el que el nuevo hegemón pudiera tener más influencia que en las Américas. En este libro, Arturo Santa-Cruz discute cómo Estados Unidos ha ejercido el poder en la región en las últimas cinco décadas.

El ejercicio del poder, conforme la visión expuesta por Santa-Cruz, debe ser entendido en términos de relaciones sociales, lente que utiliza para hacer un cuidadoso escrutinio de la evolución de las relaciones de Estados Unidos con otros países del hemisferio occidental, en el ámbito económico. La elección de esta región para entender los vaivenes de la hegemonía estadounidense no es casualidad: además de ser su histórica área de influencia, la presencia de ciertos países con los que ha sostenido relaciones muy diferentes a lo largo del periodo seleccionado permite hacer un análisis mucho más concienzudo de

1. Universidad de Guadalajara, Centro de Estudios sobre América del Norte del Departamento de Estudios del Pacífico y Presidente de la Australian and New Zealand Studies Association of North America. Av. Parres Arias 150, Los Belenes, Zapopan, Jalisco, México. ORCID: 0000-00015251-1994 Correo electrónico: miguel.hijar@csh.udg.mx 
la práctica del poder estadounidense en América del Norte, América Central y América del Sur, respectivamente.

La obra se divide en ocho capítulos en los que el autor hace una discusión teórica y empírica acerca de la hegemonía, el poder y la política, así como del complejo ejercicio del poder económico en las relaciones del hegemón con Canadá, México, Centroamérica y Sudamérica.

El primer capítulo aborda el largo - y aún incompleto- debate que ha tenido lugar en la literatura de las Relaciones Internacionales en los últimos 50 años sobre el declive de la hegemonía estadounidense, así como los diferentes referentes y estándares utilizados en la discusión. Además de ahondar en el debate y sus implicaciones, Santa-Cruz discute las condiciones y los medios que permitieron a Washington alcanzar su estatus hegemónico al final de la Segunda Guerra Mundial y mantenerlo durante y después de la Guerra Fría, así como las relaciones de anarquía y jerarquía en el hemisferio occidental.

El segundo capítulo continúa la discusión acerca de la anarquía y la jerarquía explicando la importancia de los órdenes regionales en la política internacional y describiendo el orden estadounidense y sus particularidades en específico y cómo Estados Unidos se convirtió en el hegemón del mismo desde una etapa muy temprana, así como las diferenciadas relaciones jerárquicas que estableció con Canadá, por un lado, y con América Latina, por el otro.

El capítulo tercero aborda un concepto que va de la mano de la hegemonía y que es probablemente el más importante —y a la vez quizás el más problemático- para las disciplinas de Ciencia Política y Relaciones Internacionales: poder. Así, Santa-Cruz hace un repaso de las diferentes concepciones y operacionalizaciones del poder en las teorías de Relaciones Internacionales y justifica el uso de la visión social-relacional para términos de su análisis.

El cuarto capítulo escudriña en la noción de la economía como una arena de las relaciones sociales de poder y en cómo la relación entre la economía y la política -ignorada por varias décadas en la disciplina de Relaciones Internacionales - entiende este fenómeno, es decir, cómo la Economía Política Internacional entiende el ejercicio del poder, y cómo el poder de Estados Unidos ha aumentado y disminuido durante las últimas cinco décadas en el hemisferio occidental.

Los siguientes cuatro capítulos abordan la proyección del poder estadounidense - en especial en el ámbito de la política económica - en sus relaciones con Canadá, México, América Central y América del Sur en tres diferentes etapas: 1971-1989, periodo que inicia con el famoso Nixon Shock, es decir, 
el abandono del patrón oro y otras importantes medidas en el ámbito de la política económica, y que termina con el fin de la Guerra Fría; 1990-2000, el momento unipolar en que Estados Unidos se posicionó como el hegemón incontestado; y 2001-2016, tiempo que ha visto el ascenso de otras potencias que parecen rivalizar con el poderío estadounidense en diversos ámbitos y en diversas latitudes. Estos últimos cuatro capítulos se centran en examinar si el grado de hegemonía estadounidense en las Américas ha disminuido, aumentando o permaneciendo estable a lo largo de estos tres periodos.

Este lúcido análisis, en conclusión, lleva de la mano al lector a través de la historia y la teoría para entender el ejercicio del poder de Estados Unidos por medio de su política económica en los diferentes países del hemisferio occidental, así como la propia naturaleza del poder y su impacto en los órdenes regionales. Sin embargo, el autor no se queda ahí, sino que extiende el argumento al destino de la hegemonía estadounidense en la región desde la llegada de Donald Trump a la Casa Blanca. Es por ello que este libro no sólo hace una invaluable contribución a los estudios sobre las relaciones internacionales del hemisferio occidental, sino también al debate más amplio acerca del auge y la caída de la hegemonía estadounidense que aún sostiene el orden en que vivimos, por lo que resulta una lectura indispensable para aquellos que quieran comprender el rumbo que la política internacional está tomando. 